- Review・

\title{
Satellite All-sky Infrared Radiance Assimilation: Recent Progress and Future Perspectives
}

\author{
Jun LI $^{*}$, Alan J. GEER ${ }^{2}$, Kozo OKAMOTO ${ }^{3}$, Jason A. OTKIN ${ }^{1}$, Zhiquan LIU ${ }^{4}$, Wei HAN ${ }^{5}$, and Pei WANG ${ }^{1}$ \\ ${ }^{1}$ Cooperative Institute for Meteorological Satellite Studies, University of Wisconsin-Madison, 53706, U.S.A. \\ ${ }^{2}$ European Centre for Medium-Range Weather Forecasts, Reading, RG2 9AX, U.K. \\ ${ }^{3}$ Meteorological Research Institute, Japan Meteorological Agency, Tsukuba, 305-0052, Japan \\ ${ }^{4}$ National Center for Atmospheric Research, Boulder, 80301, U.S.A. \\ ${ }^{5}$ National Meteorological Center of China Meteorological Administration, Beijing 100081, China
}

(Received 27 February 2021; revised 9 July 2021; accepted 12 August 2021)

\begin{abstract}
Satellite infrared (IR) sounder and imager measurements have become one of the main sources of data used by data assimilation systems to generate initial conditions for numerical weather prediction (NWP) models and atmospheric analysis/reanalysis. This paper reviews the development of satellite IR data assimilation in NWP in recent years, especially the assimilation of all-sky satellite IR observations. The major challenges and future directions are outlined and discussed.
\end{abstract}

Key words: satellite data assimilation, all-sky radiances, variational and ensemble data assimilation

Citation: Li, J., A. Geer, K. Okamoto, J. Otkin, Z. Q. Liu, W. Han, and P. Wang, 2022: Satellite all-sky infrared radiance assimilation: Recent progress and future perspectives. Adv. Atmos. Sci., 39(1), 9-21, https://doi.org/10.1007/s00376-0211088-9.

\section{Article Highlights:}

- A review and summary of the current satellite radiance assimilation.

- The challenges and progress of all-sky radiance assimilation.

- Future strategies for all-sky radiance assimilation.

\section{Introduction}

Sensible weather conditions are fundamentally related to the presence and characteristics of clouds, with severe weather systems usually accompanied by clouds and precipitation. Cloudy regions are forecast sensitive areas (McNally, 2002). The large horizontal and vertical gradients of atmospheric variables, such as temperature, moisture, and wind, make forecasting the weather within cloudy regions quite difficult. As a result, understanding how to effectively use information from cloudy regions is a challenging but important task for data assimilation in regional and global numerical weather prediction (NWP) modeling systems.

Satellite measurements have been playing a larger role in the global observing system (Bauer et al., 2015), particularly since the advent of direct radiance assimilation in the 1990s (Eyre et al., 2020). Operational and research satellite sensors provide observations that cover the whole globe,

\footnotetext{
* Corresponding author: Jun LI

Email: Jun.Li@ssec.wisc.edu
}

which is especially useful in areas where conventional data are sparse, such as over oceanic regions, the Southern Hemisphere, and remote land areas. These satellite measurements are also important for climate studies and calculating the global energy budget (Stephens et al., 2012). Measurements from hyperspectral infrared (IR) sounders and Microwave (MW) sounders have been widely used in NWP models and other applications (Le Marshall et al., 2005, 2006; Kelly and Thepaut, 2007; Menzel et al., 2018). Some operational centers are assimilating all-sky MW radiances. For example, the European Centre for Medium-range Weather Forecasts (ECMWF) began direct assimilation of all-sky radiances in their operational system in 2009 (Bauer et al., 2010), and it is now applied to most of the humiditysensitive microwave data in the system, providing substantial forecast impact (Geer et al., 2017). At the National Centers for Environmental Prediction (NCEP), the assimilation of all-sky MW radiances has been operational in the global forecast system (GFS) since May 2016 (Zhu et al., 2014). Kim et al. (2020) discussed the development of the Grid point Statistical Interpolation (GSI) configurations to assimil- 
ate all-sky data from MW imagers, such as the GPM Microwave Imager (GMI). In a regional assimilation context, Zhang et al. (2013) assimilated cloud-affected radiances from the Advanced Microwave Sounding Unit (AMSU-A), and Wu et al. (2019) assimilated all-sky radiance from the Advanced Technology Microwave Sounder (ATMS) in the tropical cyclones (TCs) core using the Hurricane Weather Research and Forecasting (HWRF) model. Yang et al. (2016) also demonstrated the benefit of assimilating all-sky AMSR-2 radiances for forecasts of Hurricane Sandy using the WRFDA system.

Radiance observations from IR sounders provide very important information to improve the NWP forecast skill (Pavelin et al., 2008; Panguad et al., 2009). The assimilation of clear-sky hyperspectral IR radiances from the Atmospheric Infrared Sounder (AIRS) into global models occurred as early as 2003 (Le Marshall et al., 2006; McNally et al., 2006). EUMETSAT (European Meteorological Satellite system) launched the MetOp (Meteorological Operational) satellite in 2006, carrying the Infrared Atmospheric Sounding Interferometer (IASI) as an operational meteorological sensor. The IASI radiances have been assimilated in both operational models and research studies (Hilton et al., 2009; Bormann et al., 2016). The Cross-track Infrared Sounder (CrIS) onboard the Suomi National Polar-orbiting Partnership (Suomi-NPP) and NOAA-20 is NOAA's new generation hyperspectral IR sounder, which can provide the high vertical resolution information needed for weather forecasting (Zhou et al., 2019). CrIS clear-sky radiances are assimilated in the NCEP GFS with the consideration of the cloud height and cloud mask from Visible Infrared Imaging Radiometer Suite (VIIRS) (Jung et al., 2017).

Clear-sky imager radiances from sensors onboard geostationary satellites, such as the Geostationary Operational Environmental Satellite (GOES) series, Meteosat series, Himawari series, and FengYun (FY) series, are also important components for operational data assimilation systems. Kazumori (2016) showed the impacts of the Advanced Himawari Imager (AHI) (Bessho et al., 2016) onboard Himawari-8 in the Japan Meteorological Agency (JMA) NWP system. Ma et al. (2017) evaluated the AHI data assimilated in NCEP GDAS/GFS. The GOES-16 clear-sky radiance data are generated and then assimilated at NCEP using the GSI hybrid 4DEnVar (Liu et al., 2019; Nebuda et al., 2018).

Although significant progress has been made on all-sky radiance assimilation for MW sounders (Geer et al., 2018), the assimilation of IR radiances for operational weather forecasting is mostly limited to clear skies and to above-cloud situations. The difficulties include potentially large uncertainties and biases in the radiative transfer model (RTM) (which may be linked to cloud microphysical properties that strongly affect the radiances but are not constrained by the forecast model), systematic discrepancies between the observations and the model background that may be attributed to model error in cloud variables (Li et al., 2016; Okamoto, 2017), and the nonlinearity of moist physics processes that can lead to non-Gaussian error characteristics (Errico et al., 2007). A particular difficulty of all-sky IR assimilation is that the radiances are mostly sensitive to the cloud top (along with the ice cloud microphysical properties, e.g., Vidot et al., 2015). Compared to all-sky MW assimilation, where the primary cloud sensitivity is to the vertically integrated mass of the hydrometeors, IR radiances are much more strongly sensitive to the cloud layout in both the vertical and the horizontal. In particular, this makes it harder to assimilate complex scenes of multi-layered and overlapping cloud (e.g., Prates et al., 2014). However, expanding IR sounder and imager radiance assimilation into cloudy skies is critical for effective use of the thermodynamic and cloud microphysical information from satellites to improve NWP forecasts.

Given the potential benefits, much experimentation on all-sky IR assimilation has already taken place. For the impacts of the all-sky imager radiances, Otkin and Potthast (2019) found that the assimilation of the $6.2 \mu \mathrm{m}$ band on the Spinning Enhanced Visible and Infrared Imager (SEVIRI) sensor with the observed cloud-top height or observed brightness temperature as the bias predictor (Otkin et al., 2018) had reduced the forecast error. Zhang et al. (2016) used the two perfect model observing system simulation experiments (OSSEs) to evaluate the potential impacts of assimilating all-sky infrared satellite radiances from GOES-R series. More recently, Wu et al. (2020) showed that assimilating 10-min clear-sky AHI radiances improved the prediction of a record-breaking rainstorm event using WRF-4DVar with a convective-scale setting. Many other investigations of allsky infrared geostationary radiance assimilation have been carried out and will be described later (e.g., Otkin et al., 2012a; Cintineo et al., 2016; Honda et al., 2018; Minamide and Zhang, 2018; Zhang et al., 2018, 2019a; Okamoto et al., 2019). Assimilation of all-sky IR sounder radiances is also under investigation (e.g., Okamoto et al., 2014; Geer, 2019; Geer et al., 2019).

In this paper, the methodologies and progress on assimilating the all-sky IR radiances and their impacts, as well as the challenges and future perspectives, are reviewed and discussed. Section 2 details the recent progress on indirect use of the cloudy IR observations, including regional and global NWP models. Section 3 reviews the progress of the direct assimilation of the all-sky IR radiance assimilation using the variational and ensemble Kalman filter (EnKF) methods. Section 4 outlines the potential problems and challenges, and section 5 provides future perspectives.

\section{Indirect use of cloudy IR observations}

\subsection{Assimilation of retrieved products}

Given that all-sky radiances can be difficult to assimilate due to nonlinearity and poorly constrained microphysical assumptions, one possibility is to deal with these issues outside the main data assimilation process. This can be done by performing an initial retrieval from the cloud-affected radi- 
ances, then assimilating some parts of the resulting geophysical profile into the main data assimilation system (quite possibly throwing away the cloud information). For example, this was the philosophy behind the $1 \mathrm{D}+4 \mathrm{D}-\mathrm{Var}$ assimilation of retrieved total column water vapor from cloudy microwave observations between 2006 and 2009 at ECMWF (Bauer et al., 2006). The 1D-Var designation means that the retrieval is performed by a variational method using the same background forecast as the main operational system. A recent idea is to use a Bayesian retrieval (1D-Bay+4D-Var) to more effectively deal with nonlinearity, non-Gaussianity, and unknown microphysical assumptions in the retrieval process (e.g., Duruisseau et al., 2019). The retrieval could alternatively be completely independent from the model background fields - any retrieval product could be considered for assimilation.

The main application of retrievals that is widely used for assimilating information from cloud-affected IR observations is where the cloud-top pressure (CTP) and effective cloud amount (ECA) (or effective cloud fraction) are retrieved from IR radiances and then used to constrain the cloud parameters in the RTM, so that the IR radiances can be more accurately assimilated (Pavelin et al., 2008; McNally, 2009; Pangaud et al., 2009; Lupu and McNally, 2012; Okamoto, 2013). These approaches typically retain only the channels that are weakly or moderately affected by cloud, and there are widely varying criteria for the permitted level of cloud visibility. However, the method of McNally (2009) retains all channels affected by overcast clouds, arguing that the cloud top temperature provides a measurement of the atmospheric temperature with very high vertical resolution. For all these studies, cloud overcast conditions were assumed as a single-layer cloud for the radiative transfer (RT) calculation, which significantly limited the applicable observations.

Assimilating retrieved cloud products (cloud-top properties, hydrometeor profiles, etc.) can provide important information in cloudy regions that avoids the complexity of handling cloud in the RTM (Jones et al., 2013a; Jones and Stensrud, 2015). However, hydrometeors are not used as control variables in some of the operational data assimilation systems, which makes it more difficult to assimilate information about the cloud field. As examples of the assimilation of IR-retrieved cloud products, Meng et al. (2021a) revised an observation operator of cloud liquid/ice water path (LWP \& IWP) to directly use the hydrometeor information from the NWP model, which reduced the differences between the observations and simulations. The assimilation of LWP and IWP products derived from the GOES-16 Advanced Baseline Imager (ABI) (Schmit et al., 2005) for Hurricane Irma (2017) shows improvement of water vapor both at analysis and in forecast fields. The retrieval process for deriving hydrometeor products could also introduce additional errors because of errors in the retrieval first guess as discussed by Eyre et al. (2020). Thus, observation errors need to be carefully considered and tested when assimilating cloud property retrievals.

\subsection{Assimilation of hyperspectral cloud-cleared radiances (CCRs)}

In part due to their large footprint size, the availability of IR sounder clear-sky radiances is limited, which greatly limits the use of IR sounder observations in data assimilation systems (Huang and Smith, 2004). Therefore, adding more information for cloudy footprints would help improve the satellite data applications and NWP forecasts. Given the challenges associated with assimilating cloudy IR radiances, one approach is to assimilate cloud-cleared radiances (CCRs), for which the cloud effect in the IR sounder footprint has been removed to obtain the clear-sky equivalent IR radiances. This is a longstanding way of using IR observations (Chahine, 1977; Joiner and Rokke, 2000). A more recent development is to use radiances from high spatial resolution imager pixels collocated with the hyperspectral IR sensor. Here, we focus on the imager-based cloud-clearing (CC) method developed by Goldberg et al. (2005) and Li et al. (2005), which removes the cloud effect from an IR sounder footprint containing partial cloud cover using collocated high-resolution imager IR band radiances of clear pixels within the sub-footprint. Additional quality controls (including the similarity test and homogeneous test) are further applied to ensure the quality of the CCRs. The CCRs have the same spatial resolution as the original radiance observations. After applying the CC algorithm, cloud effects on the partial cloudy sounder footprints are removed. As a result, generating clear equivalence radiances leads to an increase in the number of observations in partially cloudy regions for assimilation.

The imager-based CC approach has been successfully applied to process VIIRS/CrIS partly cloudy radiances (Wang et al., 2017). Figure 2 shows the CrIS original brightness temperature $(\mathrm{Tb})$ spectrum for the 1305 channels (green line) of the CrIS footprint in Fig. 1 for the black circle. The CrIS cloud-cleared Tb spectrum of the same footprint is shown with a blue line. After removing cloud contamination, the CrIS cloud-cleared $\mathrm{Tb}$ spectrum is warmer than the original CrIS Tb. The VIIRS IR band Tb corresponding to the same wavelength is also plotted in Fig. 2 (red star), which can be used as a clear Tb reference for the CrIS cloud-cleared $\mathrm{Tb}$. After convolving the CrIS cloud-cleared $\mathrm{Tb}$ spectrum to the corresponding VIIRS wavelengths using the spectral response functions (SRF), the convolved VIIRS $\mathrm{Tb}$ is close to the spatially averaged VIIRS Tb clear observation within the footprint, which indicates that the $\mathrm{CC}$ method can effectively remove cloud contamination from a partially cloudy CrIS footprint. Note that all the CC processing is conducted in radiance space and the CCRs are converted to $\mathrm{Tb}$ for comparisons and applications.

As shown in Fig. 3, there are approximately $48 \%$ more radiances globally that are available for assimilation, especially over ocean and in the Southern Hemisphere for this particular case. However, because the noise is amplified in the $\mathrm{CC}$ process ( $\mathrm{Li}$ et al., 2005), it is necessary to inflate the 

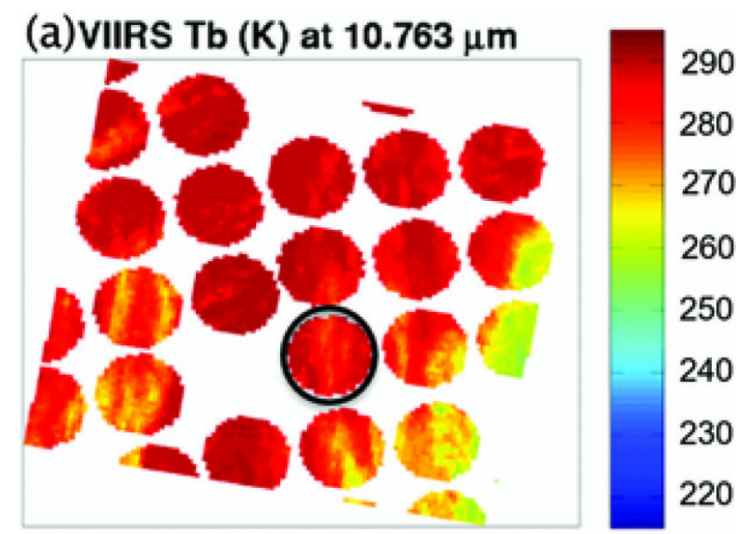

\section{(b) VIIRS Cloud Mask}

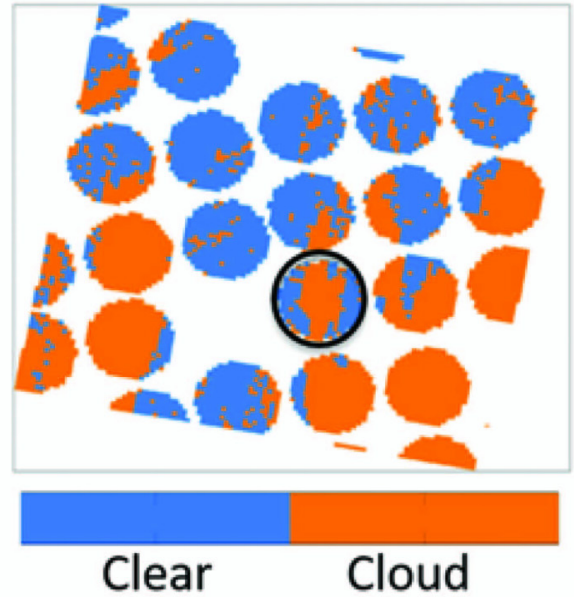

Fig. 1. VIIRS Tb image from band M 15 (wavelength $10.763 \mu \mathrm{m}$ ) (units: K) (left); and the VIIRS cloud mask overlaying on the CrIS footprints. The black circle gives an example of the $\mathrm{Tb}$ and the cloud mask coverage.

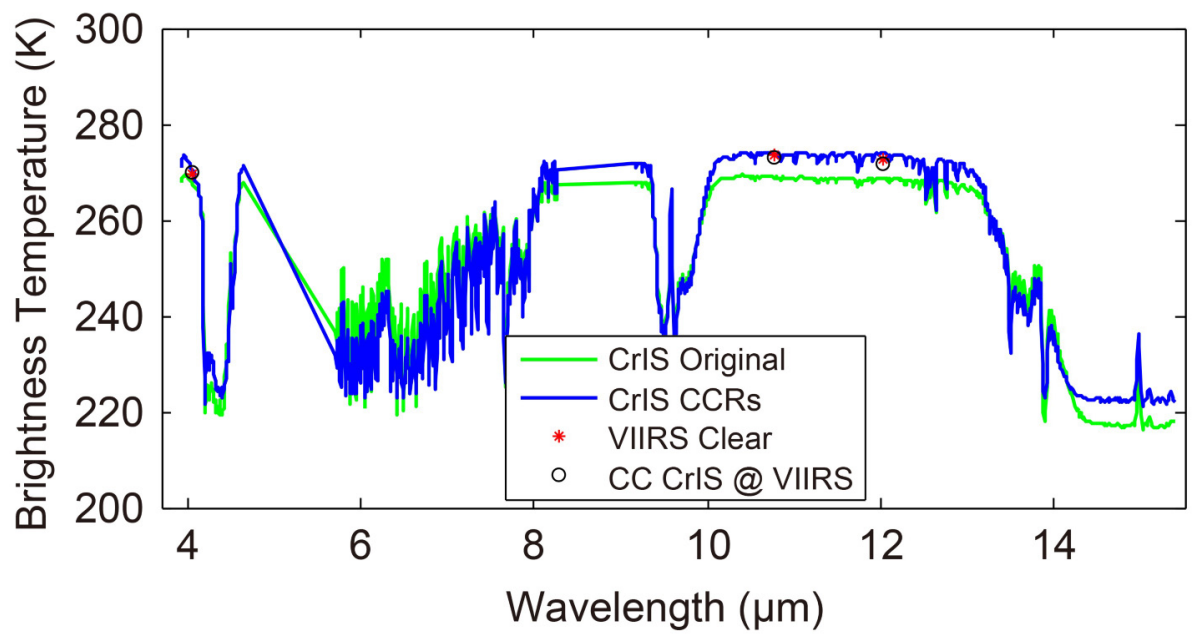

Fig. 2. The Tb spectra of the original CrIS (green line) and cloud-cleared CrIS (blue line) (units: K), respectively. The VIIRS Tb at the same wavelength is shown by red stars, and the CrIS cloud-cleared Tb convolved to VIIRS wavelength using SRF shown by black circles (units: K).

observation errors for CCR assimilation in order to optimize their use in data assimilation. A method to increase the observation errors for the CrIS CCRs by calculating the relationship between the cloudiness of the adjacent CrIS footprints had been developed and implemented in the GSI assimilation system (Wang et al., 2019). For a Hurricane Harvey (2017) study, it was found that the new assimilation approach using VIIRS-based CrIS CCRs and the inflated observation errors showed great improvements to the track forecasts due to the assimilation of more CrIS radiances, especially in cloudy skies. The intensity forecasts, such as minimum sea level pressure (SLP) and maximum wind speed (SPD), were also improved.

Assimilation of CCRs is an alternative and effective approach for assimilating thermodynamic information under partially cloudy skies (Wang et al., 2015). Global CrIS CCRs have also been generated at EMC (Environmental Modeling Center) for testing in the GFS. NCEP developed an inline $\mathrm{CC}$ algorithm in the global data assimilation system (GDAS)/GFS, and the CCRs are estimated together with all other observations (Liu et al., 2017). The AIRS CCRs have been used in the NASA Goddard Earth Observing System (GEOS, version 5) (Reale et al., 2018). The results showed that assimilating CCRs primarily affected TC representation, which was to create a strong and concentrated temperature anomaly in the upper troposphere that then translated through hydrostatic adjustment to a lower central pressure. Besides using imager data directly for IR sounder cloud detection, indirect use of imager data could also be useful, for example, when using the imager cloud mask to train the 


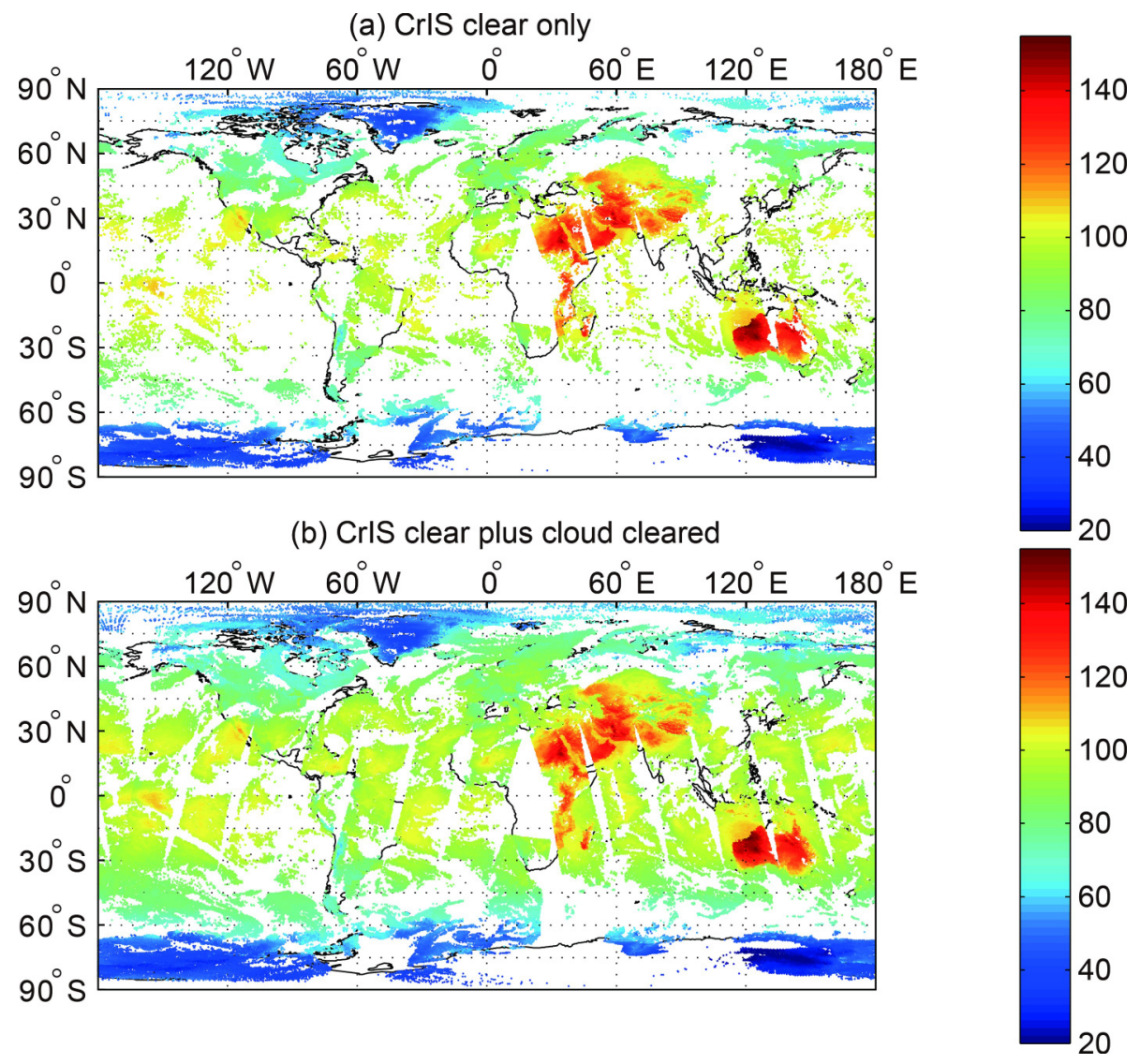

Fig. 3. The global data coverage of CrIS radiances from original CrIS clear (a) and the cloudcleared CrIS (b) at $11 \mu \mathrm{m}$ radiances [units: $\mathrm{mW}\left(\mathrm{m}^{2} \mathrm{sr} \mathrm{cm}^{-1}\right)^{-1}$ ] on 30 October 2015.

sounder cloud detection through machine learning (ML) in an offline context, while IR sounder alone cloud detection can be applied online (Zhang et al., 2019b).

The Geostationary Interferometric Infrared Sounder (GIIRS) onboard the FY-4A is the first high-spectral-resolution advanced IR sounder onboard a geostationary weather satellite, launched on 11 December 2016 (Yang et al., 2017). GIIRS can provide high temporal resolution sensitivity to the 4-D atmosphere for NWP models with the 4D-Var system (Yin et al., 2020). Figure 4 provides an example of the GIIRS observed brightness temperature minus GRAPES (Global/Regional Assimilation and PrEdiction System) background (O-B) simulations for the case of Typhoon Maria (2018) at 0200 UTC on 11 July 2018. There are an additional 371 cloud-cleared observations (denoted by triangle) added to the 420 clear sky observations (denoted by "Y") after quality control. The O-B departures from the cloudcleared observations (with standard deviation of $0.650 \mathrm{~K}$ ) are very consistent with those from clear skies (with standard deviation of $0.638 \mathrm{~K}$ ), which makes more GIIRS observations usable for assimilation. It is worth noting that placing imager and sounder sensors onboard the same geostationary platform has the advantage of characterizing the sounder sub-footprint cloud properties (Li et al., 2004) in assimilation when the sounder spatial resolution is relatively coarse (e.g., GIIRS onboard FY-4A).

\section{Direct assimilation of all-sky IR radiances}

\subsection{Assimilation of all-sky IR radiances using variational methods}

Though the direct assimilation of all-sky IR radiances is not used operationally yet, such a method is attractive because it can provide a unified treatment of clear and cloud-impacted observations that eliminates the need to use complicated cloud detection procedures (Bauer et al., 2010). All-sky data assimilation also promotes a more balanced use of satellite observations, which overcomes the tendency for data assimilation systems to assimilate a much larger number of observations in clear regions (Geer et al., 2018). Cloud-affected IR radiances in multi-layer cloud conditions were studied by Okamoto et al. (2014). A cloud effect average parameter was introduced to express the magnitude of the cloud effect. When applying this parameter, the probability density function (PDF) of O-B departures exhibits a near-Gaussian form. This method was also applied during all-sky Himwari-8/AHI IR radiance assimilation in a mesoscale model (Okamoto, 2017). The distribution of the normalized O-B was Gaussian for AHI channels 8-10, the humidity bands, with additional QC steps used to eliminate samples for which the models were unable to reproduce the observations well. Another definition of the cloud effect parameter was proposed by Harnisch et al. (2016). It uses a 


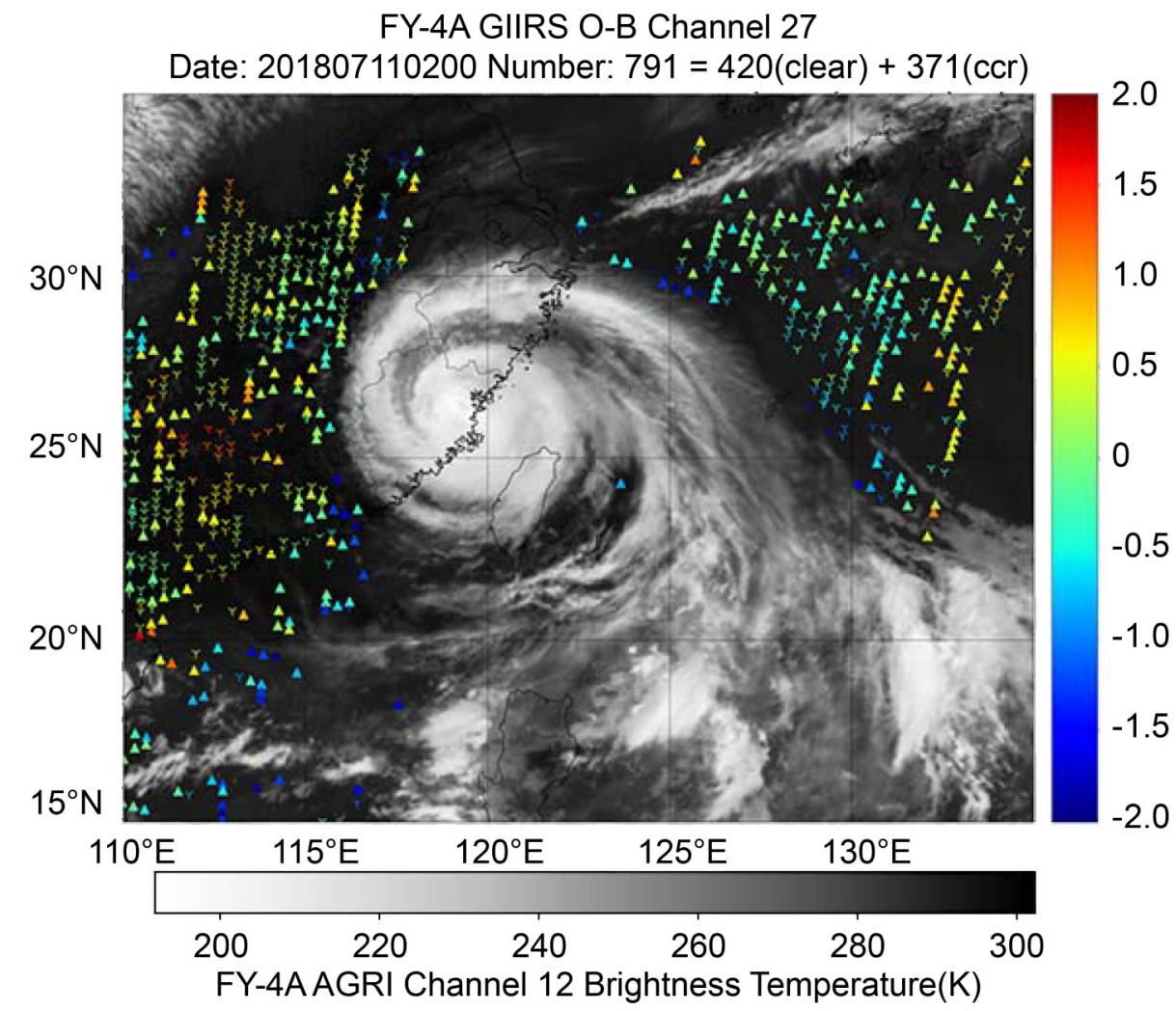

Fig. 4. FY-4A GIIRS observed brightness temperature minus GRAPES background simulations (O-B) after quality control for channel 27 (wavenumber of $761.25 \mathrm{~cm}^{-1}$ ) with the weighting function peak at around $500 \mathrm{hPa}$ in longwave band from clear-sky GIIRS radiances (denoted by "Y") and cloud-cleared radiances (denoted by triangle), overlapped on AGRI window band 12 (with central wavelength of $10.8 \mu \mathrm{m}, \mathrm{B} / \mathrm{W}$ color) at $0200 \mathrm{UTC}$ on 11 July 2018 for Typhoon Maria (2018).

fixed reference clear-sky $\mathrm{Tb}$ that was only appropriate to the locations and time period included in the original study. To make it globally applicable, the reference clear-sky $\mathrm{Tb}$ would need to be varied appropriately.

At ECMWF, a new all-sky IR configuration was tested for assimilating observations from seven IASI mid- and upper-tropospheric water vapor channels (Geer, 2019; Geer et al., 2019). RTTOV Version 12.2 with cloudy IR modeling was used as the RTM model (Saunders et al., 2018). Compared to earlier work in the ECMWF system, substantial improvements in the quality of the RT were noted, attributed to the use of a multiple independent column overlap technique (Matricardi, 2005) and to upgrades to the ice cloud microphysical assumptions (Vidot et al., 2015). The observation error model combines the inflation of error variances as a function of a symmetric cloud proxy variable with a model for error correlations that varies as a function of cloud amount (Geer, 2019). This model gives larger error standard deviations than those used in clear-sky assimilation. Therefore, the weight of all-sky radiances is smaller than the clear-sky radiances. On average across all seven channels, all-sky radiance assimilation brought $65 \%$ more data than the clear-sky radiance assimilation. Both the clear-sky and all-sky assimilation of the IASI WV soundings pro- duced more accurate surface pressure and mid- and upper-tropospheric analyses. All-sky assimilation also led to slight improvements in the tropics compared to clear-sky assimilation, but the results were more generally neutral. This approach is not yet operational at ECMWF because it would need to be completely re-structured to work with other significant developments to the treatment of hyperspectral IR assimilation, particularly a possible move to principal component (PC) or reconstructed radiance assimilation, which are proposed as ways to deal with the large data volumes, particularly from forthcoming hyperspectral imagers on geostationary platforms.

Although some progress has been achieved, directly assimilating all-sky IR radiances remains challenging in operational variational assimilation systems. However, the examples examined suggest that with sustained effort it should still be possible to achieve operational all-sky IR assimilation in the near future.

\subsection{Assimilation of all-sky IR radiances using EnKF methods}

Another burgeoning area of research is the assimilation of all-sky IR radiances in convection-allowing ensemble data assimilation systems designed to improve the forecast accuracy for high-impact weather events. Most studies have 
focused on developing methods to assimilate all-sky observations from geostationary satellite imagers because they are the only source of cloud and water vapor information with sufficient spatial and temporal resolutions to match the frequent update cycles and high spatial resolution employed by regional-scale models. There is great potential in assimilating cloud-sensitive radiances from geostationary imagers because clouds are the first observable aspect of convective features (Kurzrock et al., 2018; Gustafsson et al., 2018).

Early studies with ensemble data assimilation systems employed observing system simulation experiments (OSSEs) to examine the impact of all-sky radiance assimilation on the analysis and forecast accuracy for tropical and midlatitude weather events. Otkin (2010, 2012a) showed that assimilating all-sky radiances from the $8.5 \mu \mathrm{m}$ window band on the GOES-R (now GOES-16 and GOES-17) ABI sensor improved the accuracy of the cloud field and that the presence of small cloud features in IR images requires a short horizontal localization radius to lessen the impact of spurious correlations. Subsequent studies evaluated the impact of assimilating all-sky radiances from the three water vapor bands on the ABI and AHI sensors. Otkin (2012b) found that their assimilation improved precipitation forecasts during a winter storm across the central U.S. Likewise, Jones et al. $(2013 b, 2014)$ and Cintineo et al. (2016) showed that simultaneously assimilating all-sky ABI radiances and Doppler radar reflectivity observations produced more accurate forecasts than when each observation type was assimilated individually. This occurred because the satellite radiances helped constrain the evolution of the cloud and water vapor fields in the upper troposphere, whereas the radar observations had a positive impact on the lower troposphere. Similar benefits when assimilating allsky IR radiances were found in other studies examining their influence on mesoscale convective systems and tropical cyclones (Zupanski et al., 2011; Zhang et al., 2016; Minamide and Zhang, 2017, 2018).

Following the launch of the ABI and AHI sensors in recent years, assimilation experiments have been performed using real IR radiances from geostationary imagers. Minamide and Zhang $(2017,2018)$ developed an adaptive observation error inflation (AOEI) method to account for large representativeness errors when assimilating all-sky radiances. The AOEI method scales the observation errors as a function of the size of the first guess departures. Their data sensitivity experiments for a tropical cyclone case study showed that the assimilation of all-sky Tbs from the upper-level water vapor band on the AHI sensor improved the distribution of convection embedded in the tropical depression. This then helped the model forecasts develop a more resilient TC vortex. Honda et al. (2018) showed that assimilating AHI radiances sensitive to clouds and water vapor in the middle and upper-troposphere every $10 \mathrm{~min}$ improved the structure and predicted intensity for a rapidly intensifying tropical cyclone compared to the experiment in which the radiances were assimilated at 30-min intervals. Sawada et al. (2019) assimilated Himawari-8 infrared radiances at 10-min intervals to improve the convective predictability. Okamoto et al. (2019) demonstrated that the advantage of all-sky IR radiances compared to clear-sky radiances is due to their greater spatial and temporal availability and resultant ability to lead to more stable improvements. Several investigators have also demonstrated the benefits of assimilating geostationary imager IR radiances for tropical and severe weather events (Zhang et al., 2018, 2019b).

When using all-sky IR observations, it is important to address cloud-related biases between model and observations. One approach is to remove strongly biased situations using quality control. However, bias correction can allow additional data to be used. In the context of an EnKF system, Otkin et al. (2018) and Otkin and Potthast (2019) developed a nonlinear bias correction method for all-sky IR radiances. Results from a 5-day case study assimilating SEVIRI all-sky radiances showed that use of a third order bias correction with cloud-sensitive bias predictors improved the accuracy of the model first guess and $\mathrm{O}-\mathrm{B}$ departures for conventional observations. They also showed that it is necessary to use higher order bias predictors to account for the presence of nonlinear conditional biases in the all-sky IR O-B departures.

\section{Challenges of assimilating IR radiances in cloudy skies}

Many challenges remain to be solved to make the most effective use of all-sky IR radiances in data assimilation systems. First, the NWP model has better predictability in clear skies than in cloudy skies, which makes the background error in cloudy skies larger and more complex than in clear skies; this effect also results in inflated observation errors in data assimilation systems where the forecast model is effectively part of the observation operator (e.g., Geer and Bauer, 2011; Okamoto et al., 2014, Harnisch et al., 2016; Okamoto, 2017). Second, the descriptions of clouds might be inconsistent between satellite observations and background; for example, sometimes satellites observe clouds when the background is clear, and vice versa. Producing clouds is challenging in a clear background since the Jacobian of clouds or ensemble spread is zero (e.g., Errico et al., 2007); it is more difficult than reducing or removing clouds from the background. These issues also manifest as strong nonlinearities in the Jacobian (or tangent linear and adjoint) operators. Third, the observation operator (RTM) has a limited capability to represent the cloud structure and physical properties within an NWP grid, especially when the clouds are inhomogeneous and have a three-dimensional multi-layer vertical structure. This could be addressed with a multiple independent column approach (e.g., Matricardi, 2005), but that can be slow and memory intensive, so further development of accurate but fast RTMs with associated Jacobian function is needed in cloudy skies. Fourth, both observation error and background error often 
exhibit a non-Gaussian distribution in cloudy sky conditions, which makes the assimilation difficult. The accuracy of the background error covariance matrix is highly dependent on different cloud situations (e.g., Michel et al., 2011; Bannister et al., 2020). In addition, the observation error is also scene dependent. The observation error usually contains uncertainty sources from the detector noise, pre-processing (radiometric and spectral calibrations, geo-location, navigation, and co-registration), data processing and distribution, RTM, and representative error (due to spatial and temporal mismatch between the NWP grid and observation pixel), most of which can vary from one scene to another. In cloudy situations, an accurate estimate of the observation error is difficult to obtain due to relatively large RTM and mismatch uncertainties ( $\mathrm{Li}$ et al., 2016).

One particular challenge is the large uncertainty of representing ice-phase clouds in both microphysics schemes of forecast models and RTMs. Figure 5 shows the Himawari-8 AHI channel 9 observed and simulated brightness temperatures using CRTM-v2.3.0 and RTTOV-v12.3 with a 6-h MPAS (Model for Prediction Across Scales) (Skamarock et al., 2012) model forecast with the Thompson and WSM6 microphysics scheme, respectively. The simulation valid time is 1200 UTC on 8 August 2019, when two tropical cyclones (Lekima and Krosa) coexist. AHI data are superobbed to 30-km resolution to match the MPAS model mesh. Large discrepancies exhibited between CRTM and RTTOV and between WSM6 and Thompson microphysics are mostly associated with cold ice-phase clouds, such as those at the two TC locations. The simulations agree more closely to each other when ice clouds are removed from RTM input (not shown). One possible step to tackle this issue is to make the assumed microphysical properties in the RTM consistent with the ones in the microphysics schemes (e.g., Otkin et al., 2007; Thompson et al., 2016; Sieron et al., 2018). However, if the forecast model has an inadequate representation of the microphysics, this may not be the best approach. An alternative is to estimate the microphysical parameters directly from observations; for example, this method was used to improve the microphysical assumptions for ice clouds in RTTOV (Vidot et al., 2015).

\section{Future perspectives on assimilating IR radiances in cloudy skies}

While the hyperspectral IR sounders on board polar-orbiting satellites will continue to provide key observations for NWP, the hyperspectral IR sounders on board geostationary satellites, such as the Chinese FY-4 series and Europe's Meteosat Third Generation (MTG) series, can provide observations with high temporal resolution (better than $60 \mathrm{~min}$ for full disk coverage and better than $30 \mathrm{~min}$ for regional coverage), which is critical for capturing rapid changes in the atmospheric state. Using more data from geostationary satellites in cloudy skies for storm scale, regional and global NWP models will improve the results of the data assimila- tion and thus improve the forecast accuracy. It is worth noting that since geostationary imagers have even finer spatial and temporal resolution than the future geostationary sounders, using radiances from those imagers is also very important, especially for storm-scale applications such as Warn-on-Forecast (WoF).

While channel selection, observation error estimation, and bias correction are currently the primary focus for assimilating IR radiances and geostationary imagers, the following assimilation related problems are worth further investigation. First, the RTMs and their associated Jacobians still need improvement under cloudy sky conditions, especially under mixed and multi-layer cloudy sky conditions; and so does the RTM uncertainty estimation under various cloudy situations. Second, improvements in data assimilation methodology may be required to overcome the nonlinearity problem in cloudy skies, for example, by using appropriate control variables or by removing data or conditions that tend to have large nonlinearity. Another possible solution is to use Newtonian iteration. The big challenge in Newtonian iteration is to numerically calculate the Hessian matrix, which is almost impossible in real applications. The Hessian matrix might be calculated based on a ML model trained offline. Many other ways to deal with nonlinearity in data assimilation have been suggested, with particle filters being a strong candidate (e.g., Potthast et al., 2019). Third, while direct assimilation of IR radiances in cloudy skies is still the main focus of development, assimilation of derived products in cloudy skies is worth further attention; those products include, but are not limited to: atmospheric temperature and moisture profiles above clouds or under partially cloudy skies, cloud-top height (CTH) and cloud-base height (CBH) (when combined with visible band observations), cloud liquid and ice content. From an information content point of view, assimilation of derived products and assimilation of radiances should be equivalent under certain circumstances, for example, when the retrieval errors can be estimated and appropriately quantified for assimilation. Sometimes using retrievals could be advantageous when assimilating information from thousands of IR channels on board hyperspectral sounders (Migliorini, 2012).

Observation error estimation is always an important factor in data assimilation. Sophisticated observation error models will need to be developed under different weather and surface situations. Errors are usually inflated even in clear skies, while the observation error inflation factor is usually decided ad hoc, especially under cloudy skies. Based on the observation error estimation, regularization could be used to better balance the contributions from observations and background ( $\mathrm{Li}$ and Huang, 1999) to the increment of the atmospheric state, especially under cloudy skies. In addition, appropriately estimating the background error covariance matrix under cloudy skies is very important for successful assimilation (Meng et al., 2021b). In ensemble data assimilation, this necessitates use of adaptive covariance inflation methods. 

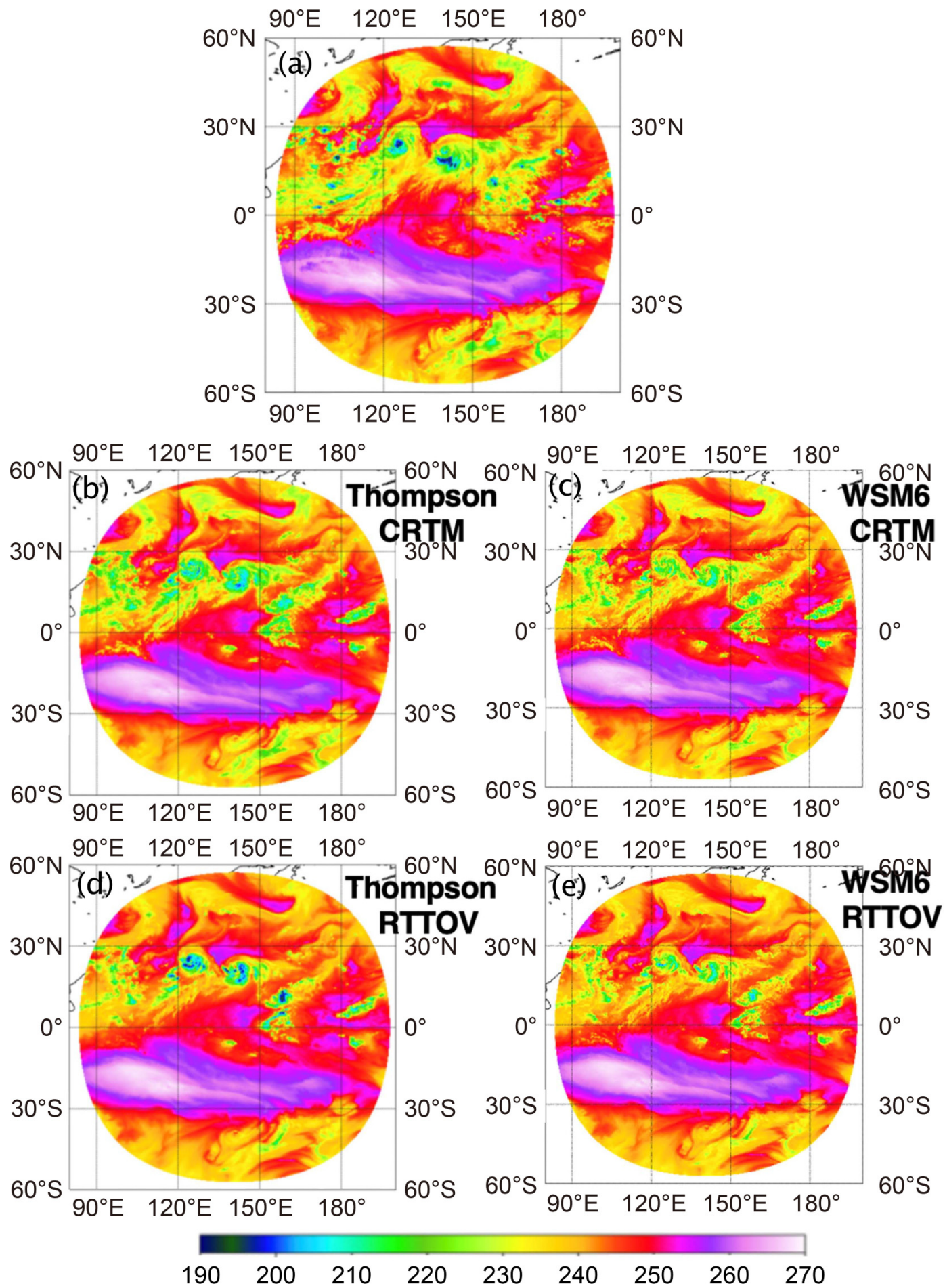

Fig. 5. AHI channel 9 observed (upper panel) and simulated brightness temperature using CRTM and RTTOV with a 6-h MPAS model forecast with Thompson and WSM6 microphysics scheme, respectively. Valid time of simulations is 1200 UTC on 8 August 2019.

ML could be a potential tool for improving IR radiance assimilation under cloudy skies. At least it can be used to derive products together with a traditional 1DVAR approach; for example, Min et al. (2020) demonstrated that combining ML and 1DVAR provides better cloud-top height estimates than with either approach alone. Enhanced QC methods that build upon ML techniques are currently being introduced to the community. Although all-sky assimilation can be conducted using stand-alone IR data, using high spatial resolution imager cloud information within the sounder sub-footprint could still be helpful for QC and observation error assignment in all-sky assimilation; for example, the sub-footprint cloud characterization (phase, fractional coverage, homogeneity, single/multi-layer, etc.) ( $\mathrm{Li}$ et al., 
2004) could provide valuable information on QC. Using multiple sources of data (imager, sounder, background, surface observations) for sounder cloud detection and all-sky IR sounder data assimilation is an important future study topic; such cloud detection could be derived through the ML model. Since the ML will be trained offline, as long as the multiple sources of data can be accessed and meet the latency, this method should be effective for real-time or near real-time (NRT) applications; the technical approaches, QC, and impact on forecasts need to be studied.

It will also be necessary to develop the schemes and approaches to support the assimilation of IR observations under all-sky conditions from CubeSats and other non-traditional observing platforms that contain complex viewing geometries (Li et al., 2019) and may have shorter lifetimes (i.e., time to characterize the errors). In addition, sophisticated observation error models and bias correction methods will need to be developed to harness the full potential of all-sky IR radiances under different weather and surface situations.

Together, these studies could lead to improved use of all-sky satellite observations, especially imager and hyperspectral IR radiance assimilation, in NWP models.

Acknowledgements. This work is partially supported by the JPSS PGRR science program (NA15NES4320001) and the NOAA Joint Technology Transfer Initiative (NA19OAR4590240) at CIMSS/University of Wisconsin-Madison.

Open Access This article is licensed under a Creative Commons Attribution 4.0 International License, which permits use, sharing, adaptation, distribution and reproduction in any medium or format, as long as you give appropriate credit to the original author(s) and the source, provide a link to the Creative Commons licence, and indicate if changes were made. The images or other third party material in this article are included in the article's Creative Commons licence, unless indicated otherwise in a credit line to the material. If material is not included in the article's Creative Commons licence and your intended use is not permitted by statutory regulation or exceeds the permitted use, you will need to obtain permission directly from the copyright holder. To view a copy of this licence, visit http://creativecommons.org/licenses/by/4.0/.

\section{REFERENCES}

Bannister, R. N., H. G. Chipilski, and O. Martinez-Alvarado, 2020: Techniques and challenges in the assimilation of atmospheric water observations for numerical weather prediction towards convective scales. Quart. J. Roy. Meteor. Soc., 146(726), 1-48, https://doi.org/10.1002/qj.3652.

Bauer, P., A. J. Geer, P. Lopez, and D. Salmond, 2010: Direct 4D-Var assimilation of all-sky radiances. Part I: Implementation. Quart. J. Roy. Meteor. Soc., 136, 1868-1885, https://doi.org/10.1002/qj.659.

Bauer, P., A. Thorpe, and G. Brunet, 2015: The quiet revolution of numerical weather prediction. Nature, 525, 47-55, https://doi.org/10.1038/nature14956.

Bauer, P., P. Lopez, A. Benedetti, D. Salmond, and E. Moreau, 2006: Implementation of 1D+4D-Varassimilation of precipita- tion-affected microwave radiances at ECMWF. I: 1D-Var. Quart. J. Roy. Meteor. Soc., 132(620), 2277-2306, https://doi.org/10.1256/qj.05.189.

Bessho, K., and Coauthors, 2016: An introduction to Himawari8/9-Japan's new-generation geostationary meteorological satellites. J. Meteor. Soc. Japan, 94, 151-183, https://doi.org/ 10.2151/jmsj.2016-009.

Bormann, N., M. Bonavita, R. Dragani, R. Eresmaa, M. Matricardi, and A. McNally, 2016: Enhancing the impact of IASI observations through an updated observation-error covariance matrix. Quart. J. Roy. Meteor. Soc., 142, 1767-1780, https://doi.org/10.1002/qj.2774.

Chahine, M. T., 1977: Remote sounding of cloudy atmospheres. II. Multiple cloud formations. J. Atmos. Sci., 34(5), 744-757, https://doi.org/10.1175/1520-0469(1977)034<07 44:RSOCAI>2.0.CO;2.

Cintineo, R. M., J. A. Otkin, T. A. Jones, S. Koch, and D. J. Stensrud, 2016: Assimilation of synthetic GOES-R ABI infrared brightness temperatures and WSR-88D radar observations in a high-resolution OSSE. Mon. Wea. Rev., 144, 3159-3180, https://doi.org/10.1175/MWR-D-15-0366.1.

Duruisseau, F., P. Chambon, E. Wattrelot, M. Barreyat, and J.-F. Mahfouf, 2019: Assimilating cloudy and rainy microwave observations from SAPHIR on board Megha Tropiques within the ARPEGE global model. Quart. J. Roy. Meteor. Soc., 145(719), 620-641, https://doi.org/10.1002/qj.3456.

Errico, R. M., P. Bauer, and J.-F. Mahfouf, 2007: Issues regarding the assimilation of cloud and precipitation data. $J$. Atmos. Sci., 64, 3785-3798, https://doi.org/10.1175/2006 JAS2044.1.

Eyre, J. R., S. J. English, and M. Forsythe, 2020: Assimilation of satellite data in numerical weather prediction. Part I: The early years. Quart. J. Roy. Meteor. Soc., 146(726), 49-68, https://doi.org/10.1002/qj.3654.

Geer, A. J., 2019: Correlated observation error models for assimilating all-sky infrared radiances. Atmospheric Measurement Techniques, 12, 3629-3657, https://doi.org/10.5194/amt-123629-2019.

Geer, A. J., and P. Bauer, 2011: Observation errors in all-sky data assimilation. Quart. J. Roy. Meteor. Soc., 137(661), 2024-2037, https://doi.org/10.1002/qj.830.

Geer, A. J., and Coauthors, 2017: The growing impact of satellite observations sensitive to humidity, cloud and precipitation. Quart. J. Roy. Meteor. Soc., 143(709), 3189-3206, https://doi.org/10.1002/qj.3172.

Geer, A. J., and Coauthors, 2018: All-sky satellite data assimilation at operational weather forecasting centres. Quart. J. Roy. Meteor. Soc., 144, 1191-1217, https://doi.org/10.1002/ qj.3202.

Geer, A. J., S. Migliorini, and M. Matricardi, 2019: All-sky assimilation of infrared radiances sensitive to mid-and upper-tropospheric moisture and cloud. Atmospheric Measurement Techniques, 12, 4903-4929, https://doi.org/10.5194/amt-124903-2019.

Goldberg, M. D., T. S. King, W. W. Wolf, C. Barnet, H. Gu, and L. H. Zhou, 2005: Using MODIS with AIRS to develop an operational cloud-cleared radiance product. Proc. SPIE 5655, Multispectral and Hyperspectral Remote Sensing Instruments and Applications II, Honolulu, Hawai'i, United States, SPIE, https://doi.org/10.1117/12.578824

Gustafsson, N., and Coauthors, 2018: Survey of data assimilation methods for convective-scale numerical weather predic- 
tion at operational centres. Quart. J. Roy. Meteor. Soc., 144, 1218-1256, https://doi.org/10.1002/qj.3179.

Harnisch, F., M. Weissmann, and Á. Periáñez, 2016: Error model for the assimilation of cloud-affected infrared satellite observations in an ensemble data assimilation system. Quart. J. Roy. Meteor. Soc., 142, 1797-1808, https://doi.org/10.1002/ qj. 2776.

Hilton, F., N. C. Atkinson, S. J. English, and J. R. Eyre, 2009: Assimilation of IASI at the Met Office and assessment of its impact through observing system experiments. Quart. J. Roy. Meteor. Soc., 135, 495-505, https://doi.org/10.1002/ qj.379.

Honda, T., and Coauthors, 2018: Assimilating all-sky Himawari8 satellite infrared radiances: A case of typhoon Soudelor (2015). Mon. Wea. Rev., 146, 213-229, https://doi.org/10.117 5/MWR-D-16-0357.1.

Huang, H.-L., and W. L. Smith, 2004: Apperception of clouds in AIRS data. Proc. ECMWF Workshop on Assimilation of High Spectral Resolution Sounder in NWP, 155-169. Available from https://www.ecmwf.int/sites/default/files/elibrary/ 2004/10054-apperception-clouds-airs-data.pdf.

Joiner, J., and L. Rokke, 2000: Variational cloud-clearing with TOVS data. Quart. J. Roy. Meteor. Soc., 126(563), 725-748, https://doi.org/10.1002/qj.49712656316.

Jones, T. A., and D. J. Stensrud, 2015: Assimilating cloud water path as a function of model cloud microphysics in an idealized simulation. Mon. Wea. Rev., 143, 2502-2081, https://doi.org/10.1175/MWR-D-14-00266.1.

Jones, T. A., D. J. Stensrud, P. Minnis, and R. Palikonda, 2013a: Evaluation of a forward operator to assimilate cloud water path into WRF-DART. Mon. Wea. Rev., 141, 2272-2289, https://doi.org/10.1175/MWR-D-12-00238.1.

Jones, T. A., J. A. Otkin, D. J. Stensrud, and K. Knopfmeier, 2013b: Assimilation of satellite infrared radiances and Doppler radar observations during a cool season observing system simulation experiment. Mon. Wea. Rev., 141, 3273-3299, https://doi.org/10.1175/MWR-D-12-00267.1.

Jones, T. A., J. A. Otkin, D. J. Stensrud, and K. Knopfmeier, 2014: Forecast evaluation of an observing system simulation experiment assimilating both radar and satellite data. Mon. Wea. Rev., 142, 107-124, https://doi.org/10.1175/ MWR-D-13-00151.1.

Jung, J. A., A. Collard, K. Bathmann, D. Groff, A. Heidinger, and M. Goldberg, 2017: Preparing for CrIS full spectral resolution radiances in the NCEP global forecast system. Proc. 21 st Int. TOVS Study Conf., Darmstadt, Germany.

Kazumori, M., 2016: Assimilation of Himawari-8 clear-sky radiance data in JMA's NWP systems. CAS/JSC WGNE Res. Activ. Atmos. Oceanic Modell., 46, 01.15-01.16.

Kelly, G., and J.-N. Thepaut, 2007: Evaluation of the impact of the space component of the global observation system through observing system experiments. ECMWF Newsletter, No. 113.

Kim, M.-J., J. J. Jin, A. E. Akkraoui, W. McCarty, R. Todling, W. Gu, and R. Gelaro, 2020: The framework for assimilating all-sky GPM microwave imager brightness temperature data in the NASA GEOS data assimilation system. Mon. Wea. Rev., 148, 2433-2455, https://doi.org/10.1175/MWRD-19-0100.1.

Kurzrock, F., S. Cros, F. C. Ming, J. A. Otkin, A. Hutt, L. Linguet, G. Lajoie, and R. Potthast, 2018: A review of the use of geostationary satellite observations in regional-scale models for short-term cloud forecasting. Meteor. Z., 27, 277-298, https://doi.org/10.1127/metz/2018/0904.

Le Marshall, J., J. Jung, J. Derber, and R. Treadon, 2005: Airs hyperspectral data improves southern hemisphere forecasts. Aust. Meteor. Mag., 54, 57-60.

Le Marshall, J., and Coauthors, 2006: Improving global analysis and forecasting with AIRS. Bull. Amer. Meteor. Soc., 87(7), 891-895, https://doi.org/10.1175/BAMS-87-7-891.

Li, J., and H.-L. Huang, 1999: Retrieval of atmospheric profiles from satellite sounder measurements by use of the discrepancy principle. Appl. Opt., 38, 916-923, https://doi.org/10. 1364/AO.38.000916.

Li, J., W. P. Menzel, F. Y. Sun, T. J. Schmit, and J. Gurka, 2004: AIRS subpixel cloud characterization using MODIS cloud products. J. Appl. Meteorol., 43, 1083-1094, https://doi.org/ 10.1175/1520-0450(2004)043<1083:ASCCUM>2.0.CO;2.

Li, J., C.-Y. Liu, H.-L. Huang, T. J. Schmit, X. B. Wu, W. P. Menzel, and J. J. Gurka, 2005: Optimal cloud-clearing for AIRS radiances using MODIS. IEEE Trans. Geosci. Remote Sens., 43, 1266-1278, https://doi.org/10.1109/TGRS.2005.847795.

Li, J., P. Wang, H. Han, J. L. Li, and J. Zheng, 2016: On the assimilation of satellite sounder data in cloudy skies in numerical weather prediction models. Journal of Meteorological Research, 30, 169-182, https://doi.org/10.1007/s13351-0165114-2.

Li, Z. L., and Coauthors, 2019: The alternative of CubeSat-based advanced infrared and microwave sounders for high impact weather forecasting. Atmos. Ocean. Sci. Lett., 12(2), 80-90, https://doi.org/10.1080/16742834.2019.1568816.

Liu, H. X., A. Collard, and J. Derber, 2017: Comparison among three CrIS cloud-clearing radiance (CCR) products \& allsky SEVIRI radiance assimilation at NCEP. ITSC 21. [Available online from https://cimss.ssec.wisc.edu/itwg/itsc/itsc21/ program/posters/9p.09_haixia_liu.pdf]

Liu, H. X., A. Collard, J. Derber, S. Nebuda, and J. Jung, 2019: Evaluation of GOES-16 clear-sky radiance data and preliminary assimilation results at NCEP. [Available online from http://bluebook.meteoinfo.ru/uploads/2019/docs/01_Liu_Hai xia_CSRassimilation.pdf]

Lupu, C., and A. McNally, 2012: Assimilation of cloud-affected radiances from Meteosat-9 at ECMWF. EUMETSAT/ECM WF Fellowship Programme Research Rep. No. 25, 33 pp.

Ma, Z. Z., E. S. Maddy, B. L. Zhang, T. Zhu, and S. A. Boukabara, 2017: Impact assessment of Himawari-8 AHI data assimilation in NCEP GDAS/GFS with GSI. J. Atmos. Oceanic Technol., 34(4), 797-815, https://doi.org/10.1175/ JTECH-D-16-0136.1.

Matricardi, M., 2005: The inclusion of aerosols and clouds in RTIASI, the ECMWF fast radiative transfer model for the infrared atmospheric sounding interferometer. ECMWF Tech. Memorandum No. 474, 53 pp.

McNally, A. P., 2002: A note on the occurrence of cloud in meteorologically sensitive areas and the implications for advanced infrared sounders. Quart. J. Roy. Meteor. Soc., 128, 2551-2556, https://doi.org/10.1256/qj.01.206.

McNally, A. P., 2009: The direct assimilation of cloud-affected satellite infrared radiances in the ECMWF 4D-Var. Quart. J. Roy. Meteor. Soc., 135, 1214-1229, https://doi.org/10.1002/ qj. 426.

McNally, A. P., P. D. Watts, J. A. Smith, R. Engelen, G. A. Kelly, J. N. Thépaut, and M. Matricardi, 2006: The assimilation of AIRS radiance data at ECMWF. Quart. J. Roy. Met- 
eor. Soc., 132, 935-957, https://doi.org/10.1256/qj.04.171.

Meng, D. M., and Coauthors, 2021a: New observation operators for cloud liquid/ice water path from ABI and their impact on assimilation and hurricane forecasts. J. Geophys. Res., 126, e2020JD034164, https://doi.org/10.1029/2020JD034164.

Meng, D. M., Y. D. Chen, J. Li, H. L. Wang, Y. B. Wang, and T. Sun, 2021b. Cloud-dependent piecewise assimilation based on a hydrometeor-included background error covariance and its impact on regional Numerical Weather Prediction. Mon. Wea. Rev., in press, https://doi.org/10.1175/MWR-D-200419.1.

Menzel, W. P., T. J. Schmit, P. Zhang, and J. Li, 2018: Satellitebased atmospheric infrared sounder development and applications. Bull. Amer. Meteor. Soc., 99, 583-603, https://doi.org/ 10.1175/BAMS-D-16-0293.1.

Michel, Y., T. Auligné, and T. Montmerle, 2011: Heterogeneous convective-scale background error covariances with the inclusion of hydrometeor variables. Mon. Wea. Rev., 139(9), 2994-3015, https://doi.org/10.1175/2011MWR3632.1.

Migliorini, S., 2012: On the equivalence between radiance and retrieval assimilation. Mon. Wea. Rev., 140(1), 258-265, https://doi.org/10.1175/MWR-D-10-05047.1.

Min, M., J. Li, F. Wang, Z. J. Liu, and W. P. Menzel, 2020: Retrieval of cloud top properties from advanced geostationary satellite imager measurements based on machine learning algorithms. Remote Sens. Environ., 239, 111616, https://doi.org/10.1016/j.rse.2019.111616.

Minamide, M., and F. Q. Zhang, 2017: Adaptive observation error inflation for assimilating all-sky satellite radiance. Mon. Wea. Rev., 145, 1063-1081, https://doi.org/10.1175/ MWR-D-16-0257.1.

Minamide, M., and F. Q. Zhang, 2018: Assimilation of all-sky infrared radiances from Himawari-8 and impacts of moisture and hydrometer initialization on convection-permitting tropical cyclone prediction. Mon. Wea. Rev., 146, 3241-3258, https://doi.org/10.1175/MWR-D-17-0367.1.

Nebuda, S., J. Jung, A. Heidinger, and A. Collard, 2018: Application of the GOES-R series cloud mask to generate clear sky and all sky radiance products for data assimilation. CGMS International Cloud Working Group, Madison, WI, 24 pp.

Okamoto, K., 2013: Assimilation of overcast cloudy infrared radiances of the geostationary MTSAT-1R imager. Quart. J. Roy. Meteor. Soc., 139, 715-730, https://doi.org/10.1002/ qj.1994.

Okamoto, K., 2017: Evaluation of IR radiance simulation for allsky assimilation of Himawari-8/AHI in a mesoscale NWP system. Quart. J. Roy. Meteor. Soc., 143, 1517-1527, https://doi.org/10.1002/qj.3022.

Okamoto, K., A. P. McNally, and W. Bell, 2014: Progress towards the assimilation of all-sky infrared radiances: An evaluation of cloud effects. Quart. J. Roy. Meteor. Soc., 140, 1603-1614, https://doi.org/10.1002/qj.2242.

Okamoto, K., Y. Sawada, and M. Kunii, 2019: Comparison of assimilating all-sky and clear-sky infrared radiances from Himawari-8 in a mesoscale system. Quart. J. Roy. Meteor. Soc., 145, 745-766, https://doi.org/10.1002/qj.3463.

Otkin, J. A., 2010: Clear and cloudy sky infrared brightness temperature assimilation using an ensemble Kalman filter. J. Geophys. Res., 115, D19207, https://doi.org/10.1029/2009JD 013759.

Otkin, J. A., 2012a: Assessing the impact of the covariance localization radius when assimilating infrared brightness temperat- ure observations using an ensemble Kalman filter. Mon. Wea. Rev., 140, 543-561, https://doi.org/10.1175/MWR-D11-00084.1.

Otkin, J. A., 2012b: Assimilation of water vapor sensitive infrared brightness temperature observations during a high impact weather event. J. Geophys. Res., 117, D19203, https://doi.org/10.1029/2012JD017568.

Otkin, J. A., and R. Potthast, 2019: Assimilation of all-sky SEVIRI infrared brightness temperatures in a regional-scale ensemble data assimilation system. Mon. Wea. Rev., 147, 4481-4509, https://doi.org/10.1175/MWR-D-19-0133.1.

Otkin, J. A., D. J. Posselt, E. R. Olson, H.-L. Huang, J. E. Davies, J. Li, and C. S. Velden, 2007: Mesoscale numerical weather prediction models used in support of infrared hyperspectral measurement simulation and product algorithm development. J. Atmos. Oceanic Technol., 24, 585-601, https://doi.org/10.1175/JTECH1994.1.

Otkin, J. A., R. Potthast, and A. S. Lawless, 2018: Nonlinear bias correction for satellite data assimilation using Taylor series polynomials. Mon. Wea. Rev., 146, 263-285, https://doi.org/ 10.1175/MWR-D-17-0171.1.

Pangaud T, N. Fourrie, V. Guidard, M. Dahoui, and F. Rabier, 2009: Assimilation of AIRS radiances affected by mid-to low-level clouds. Mon. Wea. Rev., 137, 4276-4292, https://doi.org/10.1175/2009MWR3020.1.

Pavelin, E. G., and S. J. English, and J. R. Eyre, 2008: The assimilation of cloud-affected infrared satellite radiances for numerical weather prediction. Quart. J. Roy. Meteor. Soc., 134, 737-749, https://doi.org/10.1002/qj.243.

Potthast, R., A. Walter, and A. Rhodin, 2019: A localized adaptive particle filter within an operational NWP framework. Mon. Wea. Rev., 147, 345-362, https://doi.org/10.1175/M WR-D-18-0028.1.

Prates, C., S. Migliorini, S. English, and E. Pavelin, 2014: Assimilation of satellite infrared sounding measurements in the presence of heterogeneous cloud fields. Quart. J. Roy. Meteor. Soc., 140(683), 2062-2077, https://doi.org/10.1002/qj.2279.

Reale, O., E. L. McGrath-Spangler, W. McCarty, D. Holdaway, and R. Gelaro, 2018: Impact of adaptively thinned AIRS cloud-cleared radiances on tropical cyclone representation in a global data assimilation and forecast system. Wea. Forecasting, 33, 909-931, https://doi.org/10.1175/WAF-D-170175.1.

Saunders, R., and Coauthors, 2018: An update on the RTTOV fast radiative transfer model (currently at version 12). Geoscientific Model Development, 11, 2717-2737, https://doi.org/10.5194/gmd-11-2717-2018.

Sawada, Y., K. Okamoto, M. Kunii, and T. Miyoshi, 2019: Assimilating every-10-minute Himawari- 8 infrared radiances to improve convective predictability. J. Geophys. Res., 124, 2546-2561, https://doi.org/10.1029/2018JD029643.

Schmit, T. J., M. M. Gunshor, W. P. Menzel, J. J. Gurka, J. Li, and A. S. Bachmeier, 2005: Introducing the next-generation advanced baseline imager on GOES-R. Bull. Amer. Meteor. Soc., 86, 1079-1096, https://doi.org/10.1175/BAMS-86-81079.

Sieron, S. B., F. Q. Zhang, E. E. Clothiaux, L. N. Zhang, and Y. H. Lu, 2018: Representing precipitation ice species with both spherical and nonspherical particles for radiative transfer modeling of microphysics-consistent cloud microwave scattering properties. Journal of Advances in Modeling Earth Systems, 10, 1011-1028, https://doi.org/10.1002/ 
2017MS001226.

Skamarock, W. C., J. B. Klemp, M. G. Duda, L. D. Fowler, S.-H. Park, and T. D. Ringler, 2012: A multiscale nonhydrostatic atmospheric model using centroidal voronoi tesselations and C-grid staggering. Mon. Wea. Rev., 240, 3090-3105, https://doi.org/10.1175/MWR-D-11-00215.1.

Stephens, G. L., and Coauthors, 2012: An update on Earth's energy balance in light of the latest global observations. Nature Geoscience, 5, 691-696, https://doi.org/10.1038/ ngeo1580.

Thompson, G., M. Tewari, K. Ikeda, S. Tessendorf, C. Weeks, J. Otkin, and F. Y. Kong, 2016: Explicitly-coupled cloud physics and radiation parameterizations and subsequent evaluation in WRF high-resolution convective forecasts. Atmospheric Research, 168, 92-104, https://doi.org/10.1016/ j.atmosres.2015.09.005.

Vidot, J., A. J. Baran, and P. Brunel, 2015: A new ice cloud parameterization for infrared radiative transfer simulation of cloudy radiances: Evaluation and optimization with IIR observations and ice cloud profile retrieval products. J. Geophys. Res., 120(14), 6937-6951, https://doi.org/10.1002/2015 JD023462.

Wang, P., and Coauthors, 2015: Assimilation of thermodynamic information from advanced infrared sounders under partially cloudy skies for regional NWP. J. Geophys. Res., 120, 5469-5484, https://doi.org/10.1002/2014JD022976.

Wang, P., J. Li, Z. L. Li, A. H. N. Lim, J. L. Li, T. J. Schmit, and M. D. Goldberg, 2017: The impact of cross-track infrared sounder (CrIS) cloud-cleared radiances on hurricane Joaquin (2015) and Matthew (2016) forecasts. J. Geophys. Res., 122, 13201-13218, https://doi.org/10.1002/2017JD027515.

Wang, P., J. Li, Z. L. Li, A. H. N. Lim, J. L. Li, and M. D. Goldberg, 2019: Impacts of observation errors on hurricane forecasts when assimilating hyperspectral infrared sounder radiances in partially cloudy skies. J. Geophys. Res., 124, 10802-10813, https://doi.org/10.1029/2019JD031029.

Wu, T.-C., M. Zupanski, L. D. Grasso, C. D. Kummerow, and S.A. Boukabara, 2019: All-sky radiance assimilation of ATMS in HWRF: A demonstration study. Mon. Wea. Rev., 147, 85-106, https://doi.org/10.1175/MWR-D-17-0337.1.

Wu, Y. L., Z. Q. Liu, and D. Q. Li, 2020: Improving forecasts of a record-breaking rainstorm in Guangzhou by assimilating every 10-min AHI radiances with WRF 4DVAR. Atmospheric Research, 239, 104912, https://doi.org/10.1016/ j.atmosres.2020.104912.

Yang, C., Z. Q. Liu, J. Bresch, S. R. H. Rizvi, X.-Y. Huang, and J. Z. Min, 2016: AMSR2 all-sky radiance assimilation and its impact on the analysis and forecast of Hurricane Sandy with a limited-area data assimilation system. Tellus A: Dynamic Meteorology and Oceanography, 68, 30917, https://doi.org/10.3402/tellusa.v68.30917.
Yang, J., Z. Q. Zhang, C. Y. Wei, F. Lu, and Q. Guo, 2017: Introducing the new generation of Chinese geostationary weather satellites, Fengyun-4. Bull. Amer. Meteor. Soc., 98(8), 1637-1658, https://doi.org/10.1175/BAMS-D-16-0065.1.

Yin, R. Y., W. Han, Z. Q. Gao, and D. Di, 2020: The evaluation of FY4A's Geostationary Interferometric Infrared Sounder (GIIRS) long-wave temperature sounding channels using the GRAPES global 4D-Var. Quart. J. Roy. Meteor. Soc., 146, 1459-1476, https://doi.org/10.1002/qj.3746.

Zhang, F. Q., M. Minamide, and E. E. Clothiaux, 2016: Potential impacts of assimilating all-sky infrared satellite radiances from GOES-R on convection-permitting analysis and prediction of tropical cyclones. Geophys. Res. Lett., 43, 2954-2963, https://doi.org/10.1002/2016GL068468.

Zhang, F. Q., M. Minamide, R. G. Nystrom, X. C. Chen, S.-J. Lin, and L. M. Harris, 2019a: Improving Harvey forecasts with next-generation weather satellites: Advanced hurricane analysis and prediction with assimilation of GOES-R all-sky radiances. Bull. Amer. Meteor. Soc., 100, 1217-1222, https://doi.org/10.1175/BAMS-D-18-0149.1.

Zhang, M., M. Zupanski, M.-J. Kim, and J. A. Knaff, 2013: Assimilating AMSU-A radiances in the TC core area with NOAA operational HWRF (2011) and a hybrid data assimilation system: Danielle (2010). Mon. Wea. Rev., 141, 3889-3907, https://doi.org/10.1175/MWR-D-12-00340.1.

Zhang, Q., Y. Yu, W. M. Zhang, T. L. Luo, and X. Wang, 2019b: Cloud detection from FY-4A's geostationary interferometric infrared sounder using machine learning approaches. Remote Sensing, 11(24), 3035, https://doi.org/10.3390/ rs11243035.

Zhang, Y. J., F. Q. Zhang, and D. J. Stensrud, 2018: Assimilating all-sky infrared radiances from GOES-16 ABI using an ensemble Kalman filter for convection-allowing severe thunderstorms prediction. Mon. Wea. Rev., 146, 3363-3381, https://doi.org/10.1175/MWR-D-18-0062.1.

Zhou, L. H., M. Divakarla, X. P. Liu, A. Layns, and M. Goldberg, 2019: An overview of the science performances and calibration/validation of joint polar satellite system operational products. Remote Sensing, 11(6), 698, https://doi.org/10. 3390/rs11060698.

Zhu, Y. Q., J. Derber, A. Collard, D. Dee, R. Treadon, G. Gayno, and J. A. Jung, 2014: Enhanced radiance bias correction in the National Centers for Environmental Prediction's Gridpoint Statistical Interpolation data assimilation system. Quart. J. Roy. Meteor. Soc., 140(682), 1479-1492, https://doi.org/10.1002/qj.2233.

Zupanski, D., M. Zupanski, L. D. Grasso, R. Brummer, I. Jankov, D. Lindsey, M. Sengupta, and M. Demaria, 2011: Assimilating synthetic GOES-R radiances in cloudy conditions using an ensemble-based method. Int. J. Remote Sens., 32, 9637-9659, https://doi.org/10.1080/01431161.2011.572094. 